\title{
High incidence of other primary malignancies in patients with synchronous multiple gastric cancers "a multi-center retrospective cohort study"
}

\author{
Daisuke Takeuchi ${ }^{1}$, Naohiko Koide ${ }^{2}$, Akira Suzuki ${ }^{1}$, Fumiaki Shimizu ${ }^{3}$, Yoshinori \\ Koyama ${ }^{2}$, Takehito Ehara ${ }^{1}$, Yuta Yamamoto ${ }^{1}$, Makoto Koyama ${ }^{1}$, Satoshi Nakamura ${ }^{1}$, \\ Masato Kitazawa $^{1}$, Yusuke Miyagawa ${ }^{1}$ and Shinichi Miyagawa ${ }^{1}$ \\ ${ }^{1}$ Department of Surgery, Shinshu University School of Medicine, Asahi, Matsumoto 390-8621, Japan \\ ${ }^{2}$ Department of Surgery, Nagano Prefectural Kiso Hospital, Asahi, Matsumoto 390-8621, Japan \\ ${ }^{3}$ Department of Surgery, Shinshu Ueda Medical Center, Asahi, Matsumoto 390-8621, Japan \\ Correspondence to: Daisuke Takeuchi, email: takeuchi_daichan@yahoo.co.jp \\ Keywords: multiple gastric cancers; multiple primary cancers; other primary malignancy; gastrectomy; gastric cancer \\ Received: March 20, $2017 \quad$ Accepted: March 19, $2018 \quad$ Published: April 17, 2018 \\ Copyright: Takeuchi et al. This is an open-access article distributed under the terms of the Creative Commons Attribution License \\ 3.0 (CC BY 3.0), which permits unrestricted use, distribution, and reproduction in any medium, provided the original author and \\ source are credited.
}

\section{ABSTRACT}

This study evaluated the relationship between synchronous multiple gastric cancer and other primary malignancies. During 2002-2013, 1094 consecutive surgically treated gastric cancer patients were enrolled. Preoperatively, we performed total colonoscopy and whole-body computed tomography. When malignancies in other organs were suspected, detailed organ-specific examinations were performed. Synchronous multiple gastric cancer occurred in 102 patients $(9.3 \%)$ which was frequently observed in patients with preoperative other primary malignancies $(p<0.001)$. Preoperative other primary malignancy was an independent risk factor for synchronous multiple gastric cancer $(p=0.001$; hazard ratio: $2.145,95 \%$ confidence interval: 1.354-3.399) and an independent prognostic factor of overall survival in patients undergoing gastrectomy with curative intent $(p=0.021$; hazard ratio: 1.481, 95\% confidence interval: 1.060-2.070). Thus, patients with preoperative other primary malignancies have a high risk of synchronous multiple gastric cancer. Careful preoperative examination is recommended to improve survival.

\section{INTRODUCTION}

The detection of multiple lesions of gastric cancer (GC) has been increasing along with advances in endoscopic and pathologic examinations. Synchronous multiple GCs (SMGC) have been reported to account for $5-15 \%$ of all GC cases [1]. However, accessory lesions are generally not considered as a prognostic factor in SMGC patients $[2,3]$.

GC patients sometimes present other primary malignancies (OPMs), particularly in the colon [4]. Recent studies have demonstrated an association between SMGC and OPMs, and found that this association was frequently observed in colorectal cancer patients $[5,6]$. However, the exact relationship between SMGC and OPMs remains unclear, and it would be of clinical benefit to clarify what types of OPMs occur in SMGC patients.

With this in mind, we performed the present multicenter retrospective cohort study to clarify the relationship between SMGC and OPMs.

\section{RESULTS}

Patients

The characteristics of the study population are summarized in Figure 1. A total of 1121 consecutive patients with GC were treated surgically between 2002 and 2013 in Shinshu University Hospital, Shinshu Ueda Medical Center, and Nagano Prefectural Kiso Hospital. 
Excluding 17 patients with special types of histology, such as neuroendocrine carcinoma and squamous cell carcinoma, 1094 patients with gastric adenocarcinoma were enrolled in the present study. Of the 1094 patients with GC, 102 patients (9.3\%) had SMGC, including 80 patients with $2 \mathrm{GCs}, 18$ patients with $3 \mathrm{GCs}$, and 1 patient each with 4, 5, 6, and 7 GCs. Fifty-five patients underwent gastrectomy after non-curative resection by endoscopic submucosal dissection (ESD), and 34 patients had GC in the remnant stomach. There was no patient with a new GC detected within 1 year after gastrectomy. Seventeen patients had metachronous GC, including 3 patients treated with endoscopic submucosal dissection and 14 patients treated with gastrectomy. Including these metachronous GCs, 115 patients had multiple GC (MGC); 4 patients had both SMGC and metachronous MGC. The mean follow up period was 41.8 months.

\section{Clinicopathological features of MGC}

The clinicopathological features of the patients with or without SMGC are shown in Table 1. SMGC was significantly more frequently observed in elderly patients $(p=0.002)$ and in patients with current smoking $(p=0.032)$, differentiated adenocarcinoma $(p<0.001)$, early cancer $(p=0.001)$, negative node metastasis $(p=0.035)$, negative distant metastasis $(p=0.015)$, and preoperative OPMs $(p<$ 0.001 ) compared to in their counterparts.

The clinicopathological features of the patients with or without MGC are shown in Table 2. Similar to SMGC, MGC was significantly more frequently observed in elderly patients $(p=0.001)$, men $(p=0.036)$, and in patients with current smoking $(p=0.0499)$, differentiated adenocarcinoma ( $p<0.001)$, early cancer $(p=0.028)$, negative node metastasis $(p=0.025)$, and OPMs, including both synchronous and metachronous OPMs $(p<0.001)$, than in patients without these factors.

\section{Occurrence of OPMs during the pre- and postoperative period}

The most frequently observed malignancy in the total cohort was colorectal cancer, which was observed in 77 patients, followed by prostate and lung cancers. Malignancies of the thyroid $(p=0.031)$, esophagus $(p=0.044)$, and colorectum $(p=0.025)$ were more frequently observed in patients with SMGC than in those without (Table 3).

Both antecedent and synchronous OPMs were more frequently observed in patients with SMGC $(p=0.032$ and 0.006, respectively; Table 4). During the follow-up

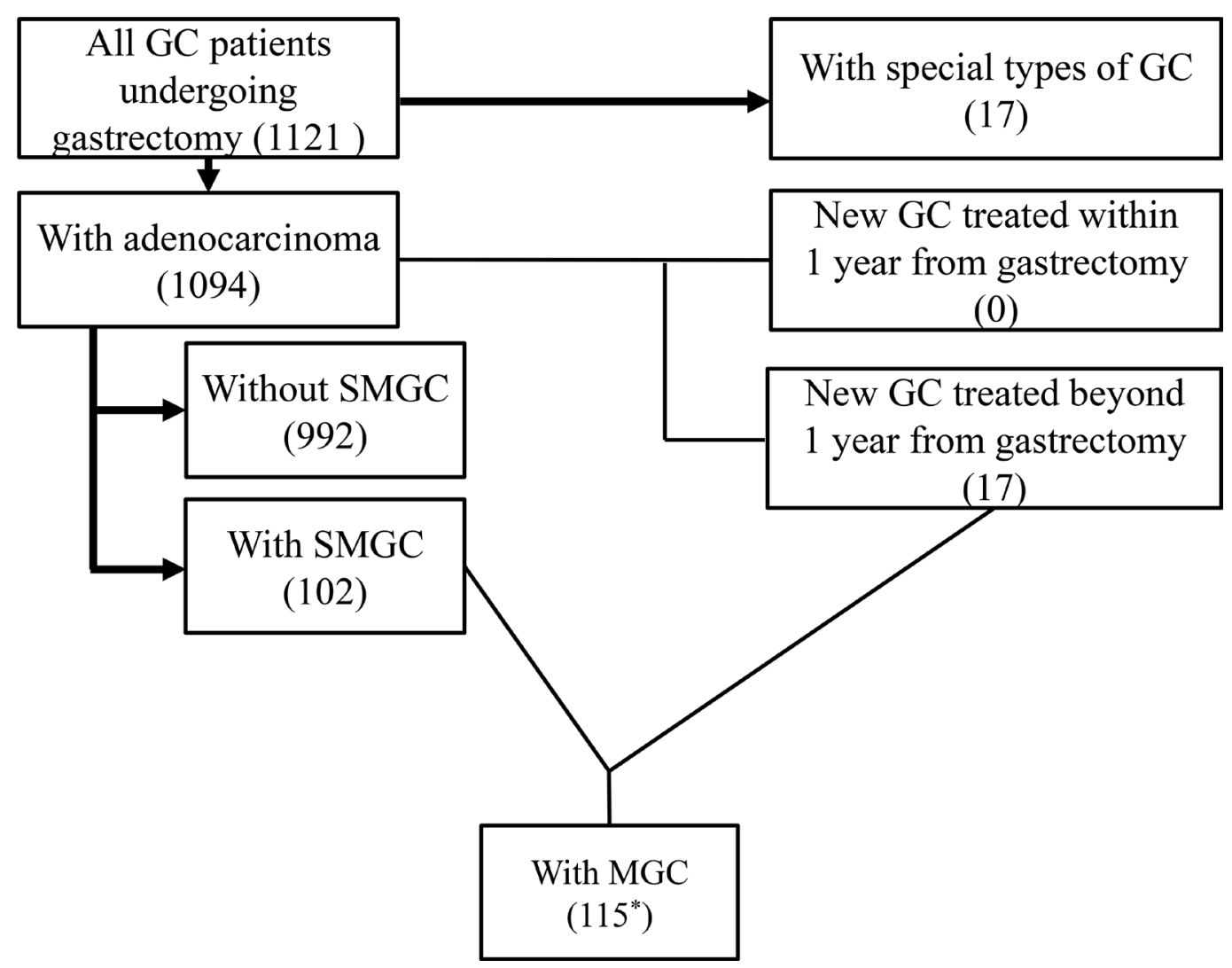

Figure 1: Characteristics of the enrolled study patients. A total of 1121 consecutive patients with gastric cancer (GC) were treated surgically between 2002 and 2013. After excluding 17 patients with special types of histology, 1094 patients with gastric adenocarcinoma were enrolled. Seventeen patients had metachronous GC. Including these metachronous GCs, 115 patients had multiple GCs (MGC). ${ }^{*}$ Four patients had both synchronous MGC (SMGC) and metachronous MGC. 
Table 1: Characteristics of patients with or without synchronous multiple gastric cancer

\begin{tabular}{|c|c|c|c|}
\hline Variable & $\begin{array}{c}\text { With SMGC } \\
\text { patients }(n=102)\end{array}$ & $\begin{array}{c}\text { Without SMGC } \\
\text { patients }(n=992)\end{array}$ & $p$-value \\
\hline Age (years old: mean \pm SD) & $73.2 \pm 10.3$ & $69.7 \pm 11.1$ & 0.002 \\
\hline Sex & & & 0.127 \\
\hline male & $77(75.5 \%)$ & $676(68.1 \%)$ & \\
\hline female & $25(24.5 \%)$ & $316(31.9 \%)$ & \\
\hline Alcohol consumption (every day) & & & 0.275 \\
\hline with & $35(34.3 \%)$ & $289(29.1 \%)$ & \\
\hline without & $67(65.7 \%)$ & $703(70.9 \%)$ & \\
\hline Current smoking & & & 0.032 \\
\hline with & $35(34.3 \%)$ & $244(24.6 \%)$ & \\
\hline without & $67(65.7 \%)$ & $748(75.4 \%)$ & \\
\hline Preoperative OPM & & & $<0.001$ \\
\hline with & $33(32.4 \%)$ & $165(16.6 \%)$ & \\
\hline without & $69(67.6 \%)$ & $827(83.4 \%)$ & \\
\hline Tumor location & & & 0.544 \\
\hline upper-third & $27(26.5 \%)$ & $240(24.2 \%)$ & \\
\hline middle-third & $35(34.3 \%)$ & $396(39.9 \%)$ & \\
\hline lower-third & $40(39.2 \%)$ & $356(35.9 \%)$ & \\
\hline Tumor size (mm: mean $\pm \mathrm{SD}$ ) & $40.9 \pm 26.1$ & $48.6 \pm 33.4$ & 0.057 \\
\hline Histologic type & & & $<0.001$ \\
\hline differentiated (tub/pap) & $77(75.5 \%)$ & $551(55.5 \%)$ & \\
\hline undifferentiated (por/sig/muc) & $25(24.5 \%)$ & $441(44.5 \%)$ & \\
\hline Depth of invasion & & & 0.001 \\
\hline pT1 & $67(65.7 \%)$ & $474(47.8 \%)$ & \\
\hline pT2 or more & $35(34.3 \%)$ & $518(52.2 \%)$ & \\
\hline Node metastasis & & & 0.035 \\
\hline pN0 & $71(69.6 \%)$ & $584(58.9 \%)$ & \\
\hline pN1or more & $31(30.4 \%)$ & $408(41.1 \%)$ & \\
\hline TNM Stage & & & $<0.001$ \\
\hline I & $74(72.5 \%)$ & $528(53.2 \%)$ & \\
\hline II & $17(16.7 \%)$ & $164(16.5 \%)$ & \\
\hline III & $9(8.8 \%)$ & $203(20.5 \%)$ & \\
\hline IV & $2(2.0 \%)$ & $97(9.8 \%)$ & \\
\hline \multicolumn{4}{|l|}{ Chemotherapy for gastric cancer } \\
\hline with & $26(25.5 \%)$ & $347(35.0 \%)$ & 0.054 \\
\hline without & $76(74.5 \%)$ & $645(65.0 \%)$ & \\
\hline BMI $\left(\mathrm{kg} / \mathrm{m}^{2}:\right.$ mean $\left.\pm \mathrm{SD}\right)$ & $22.6 \pm 4.2$ & $22.2 \pm 3.3$ & 0.618 \\
\hline Diabetes melites & & & 0.465 \\
\hline with & $17(16.7 \%)$ & $139(14.0 \%)$ & \\
\hline without & $85(8.3 \%)$ & $853(86.0 \%)$ & \\
\hline
\end{tabular}

SMGC, synchronous multiple gastric cancer; SD, standerd deviation; OPM, other primary malignancy; tub, tubular adenocarcinoma; pap, papillary adenocarcinoma; por, poorly differentiated adenocarcinoma; sig, signet ring cell carcinoma; muc, mucinous carcinoma; BMI, body mass index. 
Table 2: Characteristics of patients with solitary and multiple gastric cancer

\begin{tabular}{|c|c|c|c|}
\hline Variable & $\begin{array}{c}\text { With MGC } \\
\text { patients }(n=115)\end{array}$ & $\begin{array}{c}\text { Without MGC } \\
\text { patients }(n=979)\end{array}$ & $p$-value \\
\hline Age (years old: mean \pm SD) & $73.3 \pm 10.2$ & $69.6 \pm 11.1$ & 0.001 \\
\hline Sex & & & 0.036 \\
\hline male & $89(77.4 \%)$ & $664(67.8 \%)$ & \\
\hline female & $26(22.6 \%)$ & $315(32.2 \%)$ & \\
\hline Alcohol consumption (every day) & & & 0.675 \\
\hline with & $36(31.3 \%)$ & $288(29.4 \%)$ & \\
\hline without & $79(68.7 \%)$ & $691(70.6 \%)$ & \\
\hline Current smoking & & & 0.0499 \\
\hline with & $38(33.0 \%)$ & $241(24.6 \%)$ & \\
\hline without & $77(67.0 \%)$ & $738(75.4 \%)$ & \\
\hline $\mathrm{OPM}^{*}$ & & & $<0.001$ \\
\hline with & $43(37.4 \%)$ & $192(19.6 \%)$ & \\
\hline without & $72(62.6 \%)$ & $787(80.4 \%)$ & \\
\hline Tumor location & & & 0.058 \\
\hline upper-third & $38(33.0 \%)$ & $229(23.4 \%)$ & \\
\hline middle-third & $37(32.2 \%)$ & $394(40.2 \%)$ & \\
\hline lower-third & $40(34.8 \%)$ & $356(36.4 \%)$ & \\
\hline Tumor size (mm: mean $\pm \mathrm{SD})$ & $43.8 \pm 29.0$ & $48.33 \pm 33.3$ & 0.161 \\
\hline Histologic type & & & $<0.001$ \\
\hline differentiated (tub/pap) & $84(73.0 \%)$ & $544(55.6 \%)$ & \\
\hline undifferentiated (por/sig/muc) & $31(27.0 \%)$ & $435(44.4 \%)$ & \\
\hline Depth of invasion & & & 0.028 \\
\hline pT1 & $47(40.9 \%)$ & $506(51.7 \%)$ & \\
\hline pT2 or more & $68(59.1 \%)$ & $473(48.3 \%)$ & \\
\hline Node metastasis & & & 0.025 \\
\hline $\mathrm{pN} 0$ & $80(69.6 \%)$ & $575(58.7 \%)$ & \\
\hline pN1or more & $35(30.4 \%)$ & $404(41.3 \%)$ & \\
\hline TNM Stage & & & 0.001 \\
\hline I & $81(70.4 \%)$ & $521(53.2 \%)$ & \\
\hline II & $19(16.5 \%)$ & $162(16.5 \%)$ & \\
\hline III & $12(10.4 \%)$ & $200(20.4 \%)$ & \\
\hline IV & $3(2.6 \%)$ & $96(9.8 \%)$ & \\
\hline Chemotherapy for gastric cancer & & & 0.056 \\
\hline with & $30(26.1 \%)$ & $343(35.0 \%)$ & \\
\hline without & $85(73.9 \%)$ & $636(65.0 \%)$ & \\
\hline BMI $\left(\mathrm{kg} / \mathrm{m}^{2}:\right.$ mean $\left.\pm \mathrm{SD}\right)$ & $22.3 \pm 4.2$ & $22.2 \pm 3.3$ & 0.835 \\
\hline Diabetes melites & & & 0.463 \\
\hline with & $19(16.5 \%)$ & $137(14.0 \%)$ & \\
\hline without & $96(83.5 \%)$ & $842(86.0 \%)$ & \\
\hline
\end{tabular}

MGC, multiple gastric cancer; SD, standerd deviation; OPM, other primary malignancy; tub, tubular adenocarcinoma; pap, papillary adenocarcinoma; por, poorly differentiated adenocarcinoma; sig, signet ring cell carcinoma; muc, mucinous carcinoma; BMI, body mass index.

*OPM include pre- and postoperative cancers. 
Table 3: Solitary and synchronous multiple gastric cancer patients with other primary malignancies including preand postoperatively diagnosed

\begin{tabular}{|c|c|c|c|}
\hline $\begin{array}{l}\text { OPM } \\
\text { (pre- and postoperative) }\end{array}$ & $\begin{array}{c}\text { With SMGC } \\
\text { patients }(n=102)\end{array}$ & $\begin{array}{c}\text { Without SMGC } \\
\text { patients }(n=992)\end{array}$ & $p$-value \\
\hline Brain & $1(1.0 \%)$ & $0(0 \%)$ & 0.093 \\
\hline \multicolumn{4}{|l|}{ Head and neck } \\
\hline Oral & $1(1.0 \%)$ & $0(0 \%)$ & 0.093 \\
\hline Laryngopharynx & $0(0 \%)$ & $12(1.2 \%)$ & 0.617 \\
\hline Thyroid & $3(2.9 \%)$ & $5(0.5 \%)$ & 0.031 \\
\hline \multicolumn{4}{|l|}{ Chest } \\
\hline Lung & $5(4.9 \%)$ & $23(2.3 \%)$ & 0.174 \\
\hline Breast & $0(0 \%)$ & $13(1.3 \%)$ & 0.624 \\
\hline \multicolumn{4}{|l|}{ Gastrointestinal tract } \\
\hline Esophagus & $4(3.9 \%)$ & $11(1.1 \%)$ & 0.043 \\
\hline Colorectum & $13(12.7 \%)$ & $64(6.5 \%)$ & 0.025 \\
\hline \multicolumn{4}{|l|}{ Hepatobiliary system } \\
\hline Liver & $1(1.0 \%)$ & $13(1.3 \%)$ & 1.000 \\
\hline Bile duct & $0(0 \%)$ & $4(0.4 \%)$ & 1.000 \\
\hline Pancreas & $0(0 \%)$ & $2(0.2 \%)$ & 1.000 \\
\hline \multicolumn{4}{|l|}{ Urogenital system } \\
\hline Kidney & $2(2.0 \%)$ & $4(0.4 \%)$ & 0.101 \\
\hline Bladder & $2(2.0 \%)$ & $14(1.4 \%)$ & 0.655 \\
\hline Prostate & $5(4.9 \%)$ & $25(2.5 \%)$ & 0.190 \\
\hline Testis & $0(0 \%)$ & $2(0.2 \%)$ & 1.000 \\
\hline \multicolumn{4}{|l|}{ Gynecologic organs } \\
\hline Uterus & $0(0 \%)$ & $7(0.7 \%)$ & 1.000 \\
\hline Ovary & $0(0 \%)$ & $2(0.2 \%)$ & 1.000 \\
\hline Retroperitoneum & $1(1.0 \%)$ & $0(0 \%)$ & 0.093 \\
\hline Skin & $1(1.0 \%)$ & $4(0.4 \%)$ & 0.388 \\
\hline Hematopoietic system & $3(2.9 \%)$ & $11(1.1 \%)$ & 0.135 \\
\hline Soft tissue & $1(1.0 \%)$ & $1(0.1 \%)$ & 0.178 \\
\hline Unknown origin & $1(1.0 \%)$ & $0(0 \%)$ & 0.093 \\
\hline Total & $41(40.2 \%)$ & 194 (19.6\%) & $<0.001$ \\
\hline
\end{tabular}

OPM, other primary cancer; SMGC, synchronous multiple gastric cancer.

period, 9 OPMs were detected in 9 patients $(8.8 \%)$ with SMGC, whereas 38 OPMs were detected in 37 patients (3.7\%) without SMGC ( $p=0.031$; Table 4$)$. There was no case of OPM detected within 1 year after gastrectomy.

\section{Relationships between MGC and OPMs}

The presence of a preoperative OPM was found to be an independent risk factor for SMGC ( $p=0.001$; hazard ratio [HR]: $2.145,95 \%$ confidence interval [CI]: 1.353-3.399; Table 5), and the detection of an OPM either preoperatively or postoperatively was an independent risk factor for MGC $(p<0.001$; HR: $2.146,95 \% \mathrm{CI}$ :
1.409-3.268; Table 6). Furthermore, patients with current smoking and with SMGC frequently developed OPMs postoperatively (Table 7), and the presence of SMGC was demonstrated to be an independent risk factor for postoperative OPMs $(p=0.028$; HR: $2.35,95 \%$ CI: 1.095-5.045; Table 8).

\section{Clinical outcomes after surgery}

There were 995 patients undergoing gastrectomy with curative intent for GC. In these patients, there were no differences in the overall survival (OS) or diseasespecific survival (DSS) between the patients with 
Table 4: Other primary malignancies in patients with or without synchronous multiple gastric cancer

\begin{tabular}{lccc}
\hline Variable & $\begin{array}{c}\text { With SMGC } \\
\text { patients }(\boldsymbol{n}=\mathbf{1 0 2})\end{array}$ & $\begin{array}{c}\text { Without SMGC } \\
\text { patients }(\boldsymbol{n}=\mathbf{9 9 2})\end{array}$ & $\boldsymbol{p}$-value \\
\hline Antecedant OPM & $16(15.7 \%)$ & $90(9.1 \%)$ & 0.032 \\
$\quad$ with & $86(84.3 \%)$ & $902(90.1 \%)$ & \\
$\quad$ without & $17(16.7 \%)$ & & 0.006 \\
Synchronous OPM & $85(83.3 \%)$ & $84(8.5 \%)$ & \\
$\quad$ with & $908(91.5 \%)$ & 0.031 \\
without & $9(8.8 \%)$ & $37(3.7 \%)$ & \\
Subsequent OPM & $93(91.2 \%)$ & $955(96.3 \%)$ & \\
with & & & \\
without &
\end{tabular}

SMGC, synchronous multiple gastric cancer; OPM, other primary malignancy.

Table 5: Multivariate analysis for risk factors of synchronous multiple gastric cancer

\begin{tabular}{lccc}
\hline Variable & $\boldsymbol{p}$-value & Hazard ratio & 95\% CI \\
\hline Age (year) & 0.002 & 1.038 & $1.013-1.063$ \\
Current smoking (with) & 0.012 & 1.816 & $1.139-2.895$ \\
Preoperative OPM (with) & 0.001 & 2.145 & $1.354-3.399$ \\
Histologic type (undifferentiated) & 0.043 & 0.601 & $0.366-0.985$ \\
Depth of invasion (pT2 or more) & 0.793 & 0.92 & $0.494-1.713$ \\
Node metastasis (pN1 or more) & 0.065 & 1.794 & $0.965-3.335$ \\
Stage (I, II, III, IV) & 0.004 & 0.503 & $0.316-0.802$ \\
\hline
\end{tabular}

$\mathrm{CI}$, confidence interval; OPM, other primary malignancy.

Table 6: Multivariate analysis for risk factors of multiple gastric cancer

\begin{tabular}{lccc}
\hline Variable & p-value & Hazard ratio & 95\% CI \\
\hline Age (year) & $<0.001$ & 1.039 & $1.015-1.063$ \\
Sex (male) & 0.001 & 1.314 & $0.801-2.157$ \\
Current smoking (with) & 0.062 & 1.553 & $0.978-2.465$ \\
Pre- and postoperative OPM (with) & $<0.001$ & 2.146 & $1.409-3.268$ \\
Histologic type (undifferentiated) & 0.106 & 0.683 & $0.430-1.085$ \\
Depth of invasion (pT2 or more) & 0.284 & 1.373 & $0.769-2.453$ \\
Node metastasis (pN1 or more) & 0.193 & 1.503 & $0.814-2.777$ \\
Stage (I, II, III, IV) & 0.004 & 0.47 & $0.282-0.783$ \\
\hline
\end{tabular}

$\mathrm{CI}$, confidence interval; OPM, other primary malignancy.

$(n=100)$ and without SMGC $(n=895$ : Figure $2 \mathrm{~A}$ and $2 \mathrm{~B}$ ), or between patients with or without OPMs (Figure $3 \mathrm{~A}$ and $3 \mathrm{~B})$. However, a significantly worse OS was observed in patients with preoperative OPMs than in those without (Figure 4A), whereas there was no difference in DSS (Figure 4B). In the multivariate analysis, although the presence of SMGC was not a significant predictive factor, preoperative OPM was identified as an independent prognostic factor in patients who underwent gastrectomy with curative intent $(p=0.021$; HR: $1.481,95 \% \mathrm{CI}$ : 1.060-2.070; Table 9).

\section{DISCUSSION}

Despite great efforts of gastrointestinal endoscopists to detect second or third lesions of GC, it is difficult to 
Table 7: Characteristics of patients with and without postoperative other primary malignancies

\begin{tabular}{|c|c|c|c|}
\hline Variable & $\begin{array}{l}\text { With postoperative } \\
\text { OPM }(n=46)\end{array}$ & $\begin{array}{l}\text { Without postoperative } \\
\text { OPM }(n=1048)\end{array}$ & $p$-value \\
\hline Age (years old: mean \pm SD) & $69.0 \pm 7.9$ & $70.1 \pm 11.1$ & 0.524 \\
\hline Sex & & & 0.158 \\
\hline male & $36(78.3 \%)$ & $717(68.4 \%)$ & \\
\hline female & $10(21.7 \%)$ & $331(31.6 \%)$ & \\
\hline Alcohol consumption (every day) & & & 0.433 \\
\hline with & $16(34.8 \%)$ & 308 (29.4\%) & \\
\hline without & $30(65.2 \%)$ & $740(70.6 \%)$ & \\
\hline Current smoking & & & 0.030 \\
\hline with & $18(39.1 \%)$ & $261(24.9 \%)$ & \\
\hline without & $28(60.9 \%)$ & $787(75.1 \%)$ & \\
\hline SMGC & & & 0.032 \\
\hline with & $9(19.6 \%)$ & $93(8.9 \%)$ & \\
\hline without & $37(80.4 \%)$ & $955(91.1 \%)$ & \\
\hline Tumor location & & & 0.705 \\
\hline upper-third & $12(26.1 \%)$ & $255(24.3 \%)$ & \\
\hline middle-third & $20(43.5 \%)$ & $411(39.2 \%)$ & \\
\hline lower-third & $14(30.4 \%)$ & $382(36.5 \%)$ & \\
\hline Tumor size (mm: mean $\pm \mathrm{SD})$ & $42.9 \pm 29.1$ & $48.06 \pm 33.0$ & 0.297 \\
\hline Histologic type & & & 0.902 \\
\hline differentiated (tub/pap) & $26(56.5 \%)$ & $602(57.4 \%)$ & \\
\hline undifferentiated (por/sig/muc) & $20(43.5 \%)$ & $446(42.6 \%)$ & \\
\hline Depth of invasion & & & 0.939 \\
\hline pT1 & $23(50.0 \%)$ & $518(49.4 \%)$ & \\
\hline pT2 or more & $23(50.0 \%)$ & $530(50.6 \%)$ & \\
\hline Node metastasis & & & 0.654 \\
\hline pN0 & $29(63.0 \%)$ & $626(59.7 \%)$ & \\
\hline pN1or more & $17(37.0 \%)$ & $422(40.3 \%)$ & \\
\hline TNM Stage & & & 0.057 \\
\hline I & $27(58.7 \%)$ & $575(54.9 \%)$ & \\
\hline II & $12(26.1 \%)$ & $169(16.1 \%)$ & \\
\hline III & $7(15.2 \%)$ & $205(19.6 \%)$ & \\
\hline IV & $0(0.0 \%)$ & $99(9.4 \%)$ & \\
\hline Chemotherapy for gastric cancer & & & 0.242 \\
\hline with & $12(26.1 \%)$ & $361(34.4 \%)$ & \\
\hline without & $34(73.9 \%)$ & $687(65.6 \%)$ & \\
\hline BMI $\left(\mathrm{kg} / \mathrm{m}^{2}:\right.$ mean $\left.\pm \mathrm{SD}\right)$ & $22.0 \pm 3.0$ & $22.3 \pm 3.4$ & 0.646 \\
\hline Diabetes melites & & & 0.535 \\
\hline with & $8(17.4 \%)$ & $148(14.1 \%)$ & \\
\hline without & $38(82.6 \%)$ & $900(85.9 \%)$ & \\
\hline
\end{tabular}

SMGC, synchronous multiple gastric cancer; SD, standerd deviation; OPM, other primary malignancy; tub, tubular adenocarcinoma; pap, papillary adenocarcinoma; por, poorly differentiated adenocarcinoma; sig, signet ring cell carcinoma; muc, mucinous carcinoma; BMI, body mass index. 
Table 8: Multivariate analysis for risk factors of postoperative other primary malignancies

\begin{tabular}{lccc}
\hline Variable & p-value & Hazard ratio & 95\% CI \\
\hline Current smoking (with) & 0.049 & 1.851 & $1.004-3.415$ \\
SMGC (with) & 0.028 & 2.35 & $1.095-5.045$ \\
\hline
\end{tabular}

$\mathrm{CI}$, confidence interval; SMGC, synchronous multiple gastric cancer.

avoid missing lesions in cases of SMGC [7]. Various function-preserving procedures, such as endoscopic resection and limited gastrectomy, are performed for the treatment of GC [8]. However, these procedures lead to a larger remaining area of gastric mucosa with malignant potential in GC patients. Previous reports have demonstrated that SMGC are observed in $4-10 \%$ of GC patients $[1,7,9]$, and the present study also showed a similar proportion. There are several risk factors for SMGC, such as advanced age, differentiated histology, and early GC [1]. Accordingly, in the present study, these factors were identified as independent risk factors of SMGC, consistent with previous studies.

Previous studies have reported an incidence of OPMs of 2.6-4.7\% in GC patients [10-12]. Green et al. [13] reported that an OPM was observed in approximately $8 \%$ of advanced GC patients and $32 \%$ of early GC patients. Our previous study also showed that OPM was observed in $25 \%$ of GC patients [14]. In the present study, the incidence of OPM was $21.5 \%$. The rate was especially

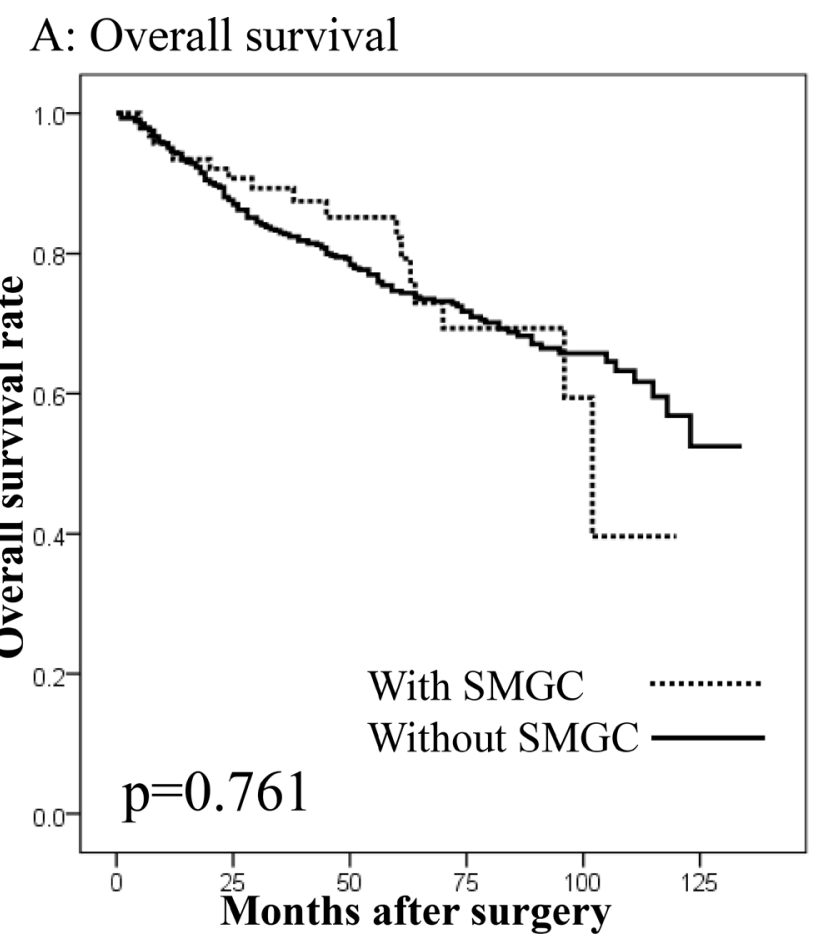

high for antecedent and synchronous OPMs, which was probably because of the high proportion of elderly patients in our study.

In these situations, a relationship between OPMs and SMGC is currently being examined. Ojima et al. [5] reported that the presence of SMGC is a risk factor of synchronous colorectal cancer, while Kim et al. [6] reported SMGC as a predictive factor for future metachronous OPMs. Taken together, these studies suggest the presence of a common oncological or epidemiological factor that causes both MGC and OPMs. Miyoshi et al. [15] reported that microsatellite instability due to mutations of mismatch repair genes plays an important role in the development of MGC. Such genetic disorders have been demonstrated to be associated with the development of colorectal cancer, as well as other cancers, such as esophagus, thyroid, and prostate cancers, among others [16-20]. A genetic disorder, like a mismatch repair gene mutation, may be a common factor underlying the development of MGC and

\section{B: Disease-specific survival}

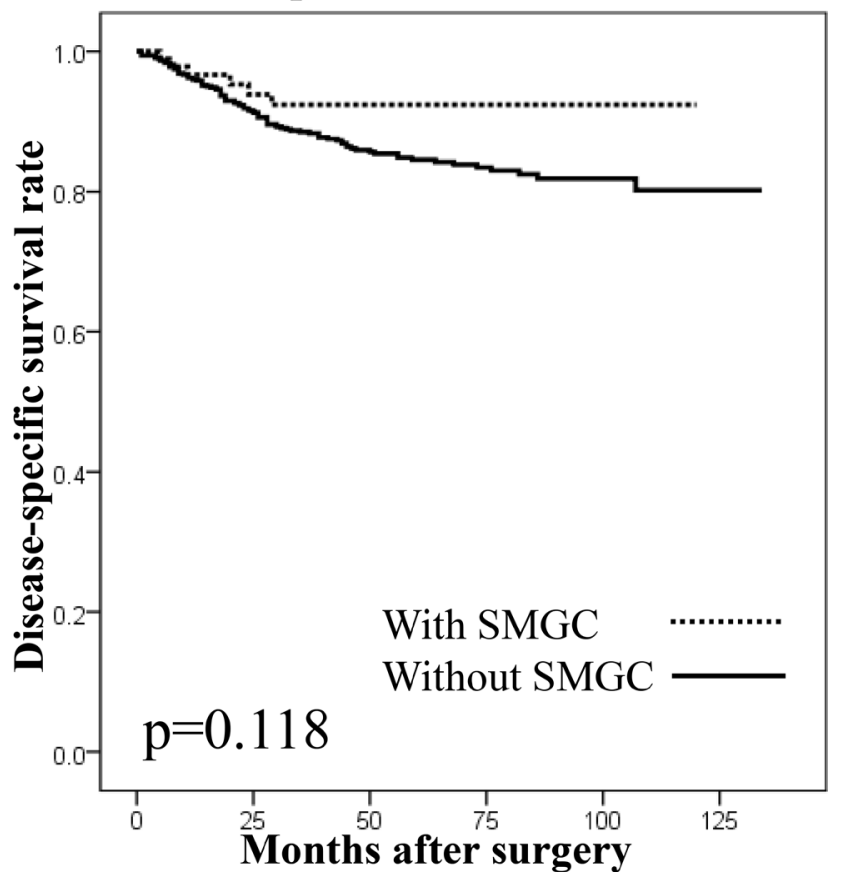

Figure 2: Survival curves of patients undergoing gastrectomy with curative intent according to the presence of synchronous multiple gastric cancers (SMGC). (A) Overall survival. No difference in overall survival was seen between patients with and without SMGC $(p=0.761)$. (B) Disease-specific survival. No difference in disease-specific survival was seen between patients with and without SMGC $(p=0.118)$. 

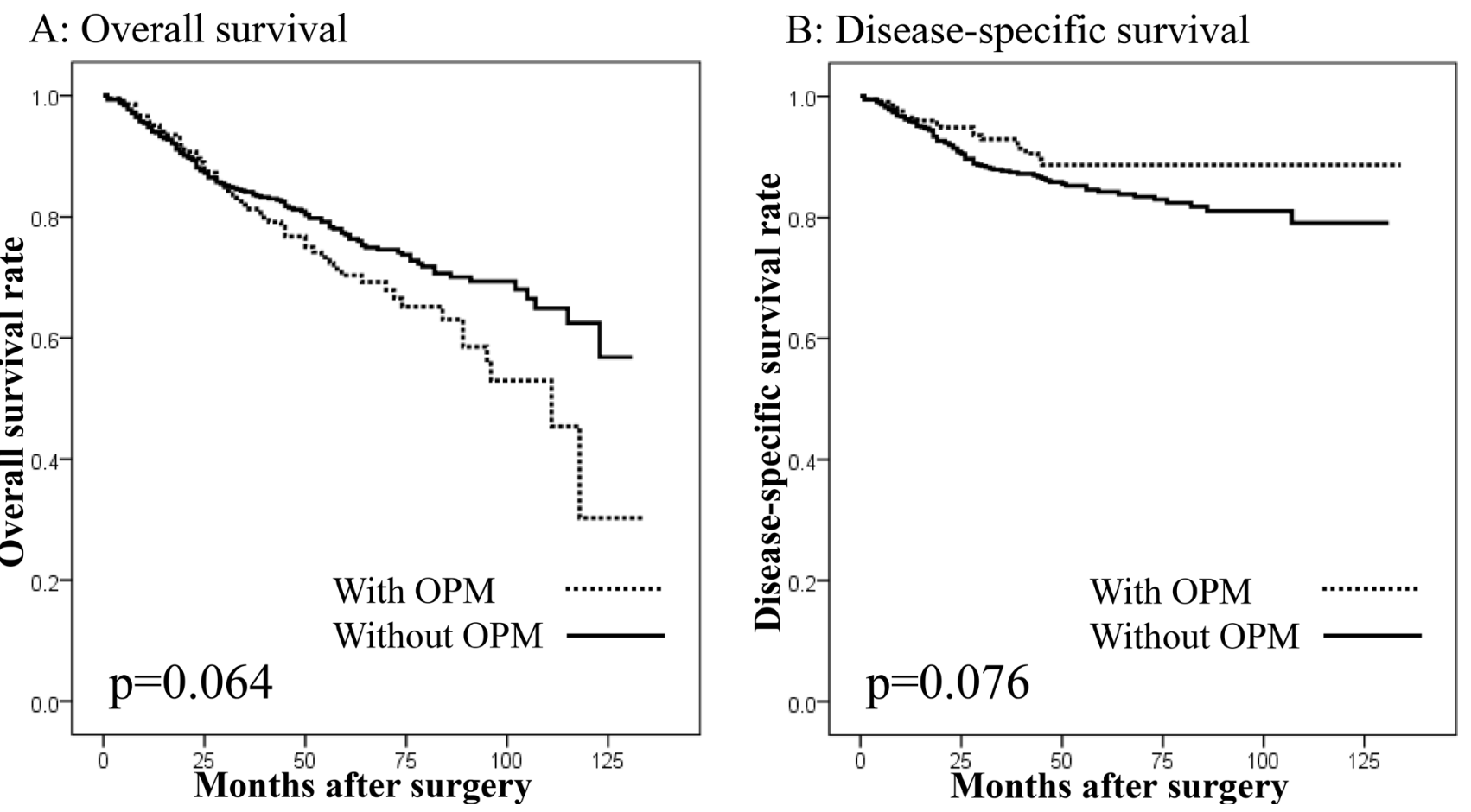

Figure 3: Survival curves in patients undergoing gastrectomy with curative intent according to the presence of other primary malignancies (OPMs). (A) Overall survival. No difference in overall survival was seen between patients with and without OPMs $(p=0.064)$. (B) Disease-specific survival. No difference in disease-specific survival was seen between patients with and without OPMs $(p=0.076)$.
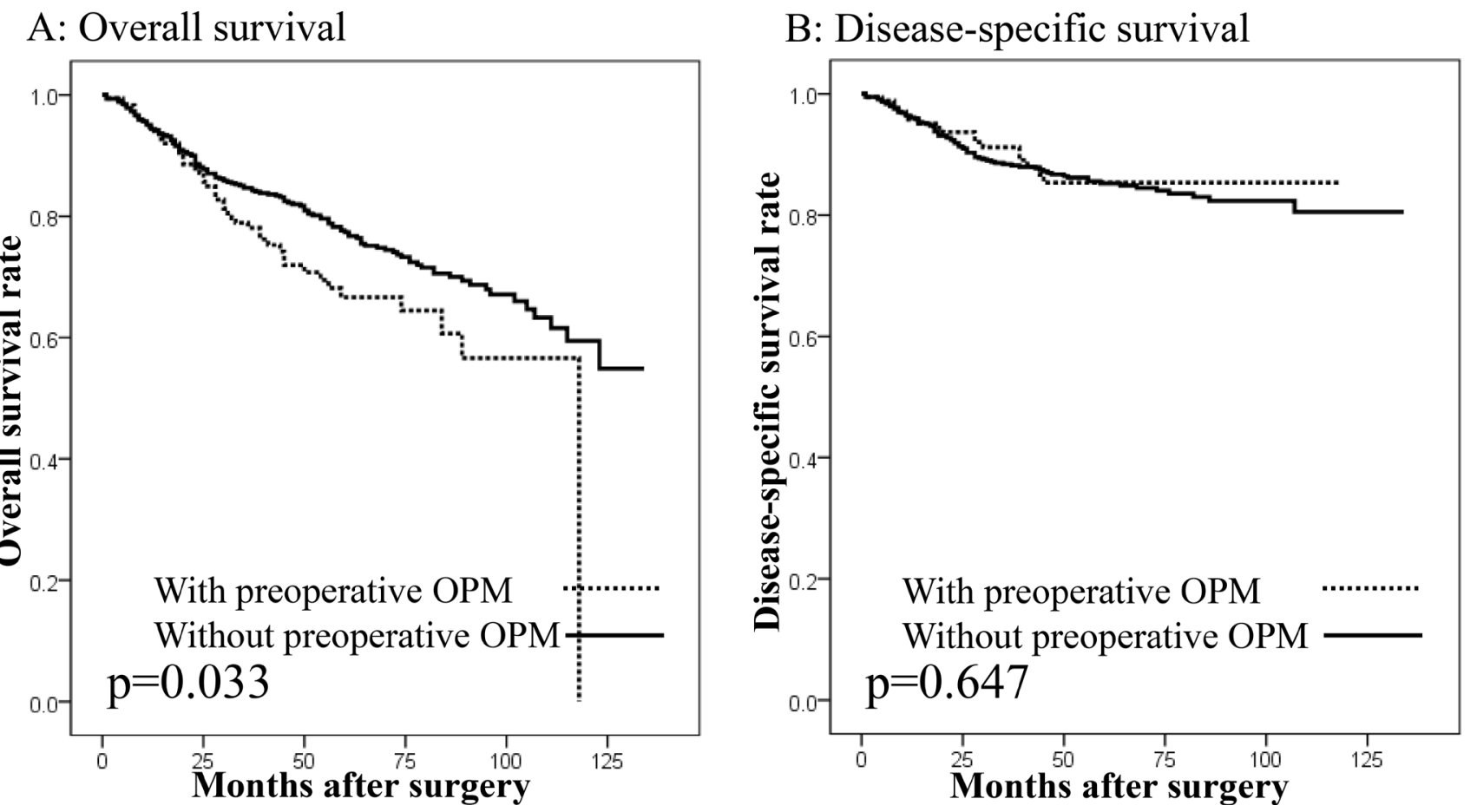

Figure 4: Survival curves in patients undergoing gastrectomy with curative intent according to the presence of other primary malignancies (OPMs) preoperatively. (A) Overall survival. Patients with preoperative OPMs showed worse overall survival than those without $(p=0.033)$. (B) Disease-specific survival. No difference in disease-specific survival was seen between patients with and without preoperative OPMs $(p=0.647)$. 
Table 9: Univariate and multivariate analysis on overall survival in gastrectomized patients with curative intent

\begin{tabular}{|c|c|c|c|c|c|c|}
\hline \multirow{2}{*}{ Variable } & \multicolumn{3}{|c|}{ Univariate analysis } & \multicolumn{3}{|c|}{ Multivariate analysis } \\
\hline & $p$-value & Hazard ratio & $95 \% \mathrm{CI}$ & $p$-value & Hazard ratio & $95 \% \mathrm{CI}$ \\
\hline Age (year) & $<0.001$ & 1.05 & $1.034-1.066$ & $<0.001$ & 1.04 & $1.024-1.055$ \\
\hline Sex (male) & 0.053 & 1.367 & $0.996-1.878$ & & & \\
\hline BMI $\left(\mathrm{kg} / \mathrm{m}^{2}\right)$ & 0.001 & 0.93 & $0.890-0.972$ & 0.104 & 0.964 & $0.923-1.008$ \\
\hline SMGC (with) & 0.761 & 0.928 & $0.571-1.506$ & & & \\
\hline Preoperative OPM (with) & 0.035 & 1.426 & $1.026-1.983$ & 0.021 & 1.481 & $1.060-2.070$ \\
\hline Histologic type (undifferentiated) & 0.093 & 1.266 & $0.960-1.666$ & & & \\
\hline Tumor size (mm) & $<0.001$ & 1.015 & $1.011-1.018$ & 0.005 & 1.007 & $1.002-1.012$ \\
\hline Tumor depth (pT2 or more) & $<0.001$ & 3.586 & $2.640-4.872$ & $<0.001$ & 1.964 & $1.368-2.820$ \\
\hline Node metastasis (pN1 or more) & $<0.001$ & 3.529 & $2.662-4.680$ & $<0.001$ & 2.03 & $1.455-2.831$ \\
\hline
\end{tabular}

CI, confidence interval; BMI, body mass index; SMGC, synchronous multiple gastric cancer; OPM, other primary malignancy.

OPMs. The present study demonstrated that the presence of SMGC is a risk factor for the occurrence of OPMs postoperatively, as well as preoperatively. Several OPMs, including thyroid, esophagus, and colorectal cancers, were noted significantly more frequently in SMGC patients, both preoperatively and postoperatively, compared to in non-SMGC patients. Therefore, SMGC patients should be carefully assessed for the presence of these cancers, and gastrointestinal endoscopists, gastroenterologist, and surgeons should keep the relationship between SMGC and OPMs in mind.

The major determinant of prognosis in $\mathrm{GC}$ patients is the cancer stage, rather than the lesion number [1]. Our results showed that there were no differences in OS or DSS between the patients with or without SMGC. On the other hand, the presence of a preoperative OPM was an independent prognostic factor for OS. Our previous study also showed that GC patients with synchronous OPMs had a worse outcome after surgery than those without it [14]. Furthermore, Kim et al. [6] regarded that the presence of synchronous and metachronous OPMs negatively affected the clinical outcome of GC survivors. Our results suggest that OPMs may be associated with an increased risk of death. To improve the outcomes of GC patients, clinicians should make particular efforts to detect OPMs in patients with SMGC. It is important to consider the possibility of OPMs, especially in the organs where OPMs frequently occur. Routine esophagogastroduodenoscopy and colonoscopy are useful for detecting esophageal and colorectal cancers, respectively. However, the detection of cancers such as prostate and thyroid cancers is associated with a number of problems, including risks of overdiagnosis and overtreatment [21, 22]. Establishment of a standardized screening method for the detection of OPMs could contribute to improved survival in SMGC patients.

Our study has some limitations. First, our data included no information regarding the patients' familial history, staging of OPMs, and Helicobacter pylori infection status. Helicobacter pylori cause chronic gastritis, leading to cancer in the stomach [23], and might contribute to the incidence of MGC. Second, the follow-up period was not enough to detect all future GCs or OPMs.

In conclusion, because patients with preoperative OPMs have a high risk of SMGC, careful preoperative examination is recommended to improve the patients' prognosis.

\section{MATERIALS AND METHODS}

\section{SMGC definition and screening}

SMGC was assessed by pathologic examination using the resected stomach samples, and the results were compared with the preoperative esophagogastroduodenoscopy findings. Multiplicity of $\mathrm{GC}$ was determined by the criteria of Moertel et al. [24], as follows: (1) two or more GCs must be pathologically proven to be malignant, (2) all lesions must be separated macroscopically by an area of normal gastric wall, and (3) the possibility that one of the lesions represents local extension of a metastatic tumor must be ruled out beyond reasonable doubt. Synchronicity of MGC was defined according to the criteria of Warren and Gates [25]. When two primary cancers were detected within 1 year, they were considered synchronous. When two primary cancers were detected more than 1 year apart, they were considered metachronous. The pathological features of the MGC were defined by main lesion, which is more advanced lesion and to be larger lesion if the depth of invasion was same.

\section{OPM definition and screening}

Multiple primary cancers arising from other organs were also defined according to the criteria of Warren and Gates [25]. Metachronous multiple primary malignancies included antecedent malignancies before surgery for GC and subsequent malignancies after surgery for GC. In order to identify preoperative risk factors for MGC, 
we classified the OPMs into two groups: a preoperative group including antecedent and synchronous OPMs, and a postoperative group including subsequent OPMs.

The histopathologic findings of GC were obtained using the resected specimens. The clinicopathologic features of GC were described according to the TNM classification ( 7 th edition).

Before surgery for GC, we performed total colonoscopy when patients were able to consume food. When colonoscopy could not be performed preoperatively, we performed it within 1 year after surgery. Furthermore, we performed whole-body computed tomography in order to detect OPMs. When malignancies were suspected in other organs, we added several examinations specific to the suspicious organs. After gastrectomy, the GC patients were followed in the outpatient clinic of each hospital not only to check for recurrence and metastasis of GC, but also to detect OPMs, by esophagogastroduodenoscopy, colonoscopy, and whole-body computed tomography. Furthermore, when the patients complained of symptoms other than those in the abdomen, we consulted clinical specialists.

\section{Statistical analysis}

Data are shown as the prevalence (\%) or mean values. Continuous variables were compared using the Mann-Whitney test, and categorical variables were compared using the Chi-square test or Fisher's exact test, depending on their distribution. Multivariate analysis of independent risk factors was carried out by multiple logistic regression tests, and prognostic factors were analyzed by Cox's proportional hazard models. The survival rates after gastrectomy were calculated by the Kaplan-Meier method. The data were analyzed using IBM SPSS 22.0 (IBM Japan, Tokyo, Japan). For all analyses, $P<0.05$ was considered significant. Missing data were accounted for using a list-wise deletion approach.

\section{Abbreviations}

CI: confidence interval; DSS: disease-specific survival; GC: gastric cancer; HR: hazard ratio; MGC: multiple gastric cancers; OPM: other primary malignancy; OS: overall survival; SMGC: synchronous multiple gastric cancers.

\section{Author contributions}

Conception and design: Daisuke Takeuchi, Naohiko Koide; Administrative support: Shinichi Miyagawa; Collection and assembly of data: Daisuke Takeuchi, Akira Suzuki, Fumiaki Shimizu, and Naohiko Koide; Data analysis and interpretation: Daisuke Takeuchi, Naohiko
Koide, Yusuke Miyagawa, and Shinichi Miyagawa; Manuscript writing: All authors.

\section{ACKNOWLEDGMENTS}

We wish to thank the help in the study given by Prof. Shinichi Miyagawa.

\section{CONFLICTS OF INTEREST}

The authors declare that they have no conflicts of interest.

\section{REFERENCES}

1. Peng J, Wang Y. Epidemiology, pathology and clinical management of multiple gastric cancers: a mini-review. Surg Oncol. 2010; 19:e110-e114.

2. Borie F, Plaisant N, Millat B, Hay JM, Fagniez PL, De Saxce B. Treatment and prognosis of early multiple gastric cancer. Eur J Surg Oncol. 2003; 29:511-514.

3. Takeshita K, Tani M, Honda T, Saeki I, Kando F, Saito N, Endo M. Treatment of primary multiple early gastric cancer: from the viewpoint of clinicopathologic features. World J Surg. 1997; 21:832-836.

4. Dinis-Ribeiro M, Lomba-Viana H, Silva R, Moreira-Dias L, Lomba-Viana R. Associated primary tumors in patients with gastric cancer. J Clin Gastroenterol. 2002; 34:533-535.

5. Ojima $T$, Iwahashi $M$, Nakamori $M$, Nakamura $M$, Katsuda M, Iida T, Hayata K, Takifuji K, Yamaguchi S, Yamaue H. Is preoperative colonoscopy necessary for patients undergoing gastric cancer surgery? Ann Surg Oncol. 2014; 21:S379-S384.

6. Kim C, Chon H, Kang B, Kim K, Jeung HC, Chung H, Noh S, Rha S. Prediction of metachronous multiple primary cancers following the curative resection of gastric cancer. BMC Cancer. 2013; 13:394.

7. Eom BW, Lee JH, Choi IJ, Kook MC, Nam BH, Ryu KW, Kim YW. Pretreatment risk factors for multiple gastric cancer and missed lesions. J Surg Oncol. 2012; 105:813-817.

8. Hiki N, Nunobe S, Kubota T, Jiang X. Function-preserving gastrectomy for early gastric cancer. Ann Surg Oncol. 2013; 20:2683-2692.

9. Kang GH, Kim CJ, Kim WH, Kang YK, Kim HO, Kim YI. Genetic evidence for the multicentric origin of synchronous multiple gastric carcinoma. Lab Invest. 1997; 76:407-417.

10. Eom BW, Lee HJ, Yoo MW, Cho JJ, Kim WH, Yang HK, Lee KU. Synchronous and metachronous cancers in patients with gastric cancer. J Surg Oncol. 2008; 98:106-110. 
11. Park YK, Kim DY, Joo JK, Kim JC, Koh YS, Ryu SY, Kim YJ, Kim SK. Clinicopathological features of gastric carcinoma patients with other primary carcinomas. Langenbecks Arch Surg. 2005; 390:300-305.

12. Wu CW, Lo SS, Chen JH, Hsieh MC, Li AF, Lui WY. Multiple primary cancers in patients with gastric cancer. Hepatogastroenterology. 2006; 53:463-467.

13. Green PH, O'Toole KM, Weinberg LM, Goldfarb JP. Early gastric cancer. Gastroenterology. 1981; 81:247-256.

14. Takeuchi D, Koide N, Komatsu D, Okumura M, Suzuki A, Miyagawa S. Relationships of obesity and diabetes mellitus to other primary cancers in surgically treated gastric cancer patients. Int J Surg. 2014; 12:587-593.

15. Miyoshi E, Haruma K, Hiyama T, Tanaka S, Yoshihara M, Shimamoto F, Chayama K. Microsatellite instability is a genetic marker for the development of multiple gastric cancers. Int J Cancer. 2001; 95:350-353.

16. Raskov H, Pommergaard HC, Burcharth J, Rosenberg J. Colorectal carcinogenesis - update and perspectives. World J Gastroenterol. 2014; 20:18151-18164.

17. Ming-Zhong S, Hui-Xiang J, Zhong-Wei Z, Hao J, Rong Z. Genetic variants of the DNA damage repair genes XRCC4 and RAD51 are associated with susceptibility to esophageal cancer. Clin Res Hepatol Gastroenterol. 2015; 39:379-383.

18. Guan H, Ji M, Hou P, Liu Z, Wang C, Shan Z, Teng W, Xing M. Hypermethylation of the DNA mismatch repair gene hMLH1 and its association with lymph node metastasis and T1799A BRAF mutation in patients with papillary thyroid cancer. Cancer. 2008; 113:247-255.

19. Mitmaker E, Alvarado C, Bégin LR, Trifiro $M$. Microsatellite instability in benign and malignant thyroid neoplasms. J Surg Res. 2008; 150:40-48.

20. Hirata H, Hinoda Y, Kawamoto K, Kikuno N, Suehiro Y, Okayama N, Tanaka Y, Dahiya R. Mismatch repair gene MSH3 polymorphism is associated with the risk of sporadic prostate cancer. J Urol. 2008; 179:2020-2024.

21. Jung M. Breast, prostate, and thyroid cancer screening tests and overdiagnosis. Curr Probl Cancer. 2017; 41:71-79.

22. Ahn HS, Kim HJ, Kim KH, Lee YS, Han SJ, Kim Y, Ko MJ, Brito JP. Thyroid Cancer Screening in South Korea Increases Detection of Papillary Cancers with No Impact on Other Subtypes or Thyroid Cancer Mortality. Thyroid. 2016; 26:1535-1540.

23. Parsonnet J, Friedman GD, Vandersteen DP, Chang Y, Vogelman JH, Orentreich N, Sibley RK. Helicobacter pylori infection and the risk of gastric carcinoma. N Engl J Med. 1991; 325:1127-1131.

24. Moertel CG, Bargen JA, Soule EH. Multiple gastric cancers; review of the literature and study of 42 cases. Gastroenterology. 1957; 32:1095-1103.

25. Warren S, Gates O. Multiple primary malignant tumors: a survey of the literature and a statistical study. Am J Cancer. $1932 ; 16: 1358-1414$. 